\title{
BMJ Open Interpretation of China's 2017 health expenditure: a latent profile analysis of panel data
}

\author{
Shuang Zang, ${ }^{1}$ Meizhen Zhao, ${ }^{2}$ Jing OuYang, ${ }^{3}$ Xin Wang (D) ${ }^{4}$
}

To cite: Zang S, Zhao M, OuYang J, et al. Interpretation of China's 2017 health expenditure: a latent profile analysis of panel data. BMJ Open 2020;10:e035512. doi:10.1136/ bmjopen-2019-035512

\section{- Prepublication history and} additional material for this paper are available online. To view these files, please visit the journal online (http://dx.doi org/10.1136/bmjopen-2019035512).

Received 06 November 2019 Revised 14 January 2020 Accepted 27 May 2020
Check for updates

\section{(C) Author(s) (or thei} employer(s)) 2020. Re-use permitted under CC BY-NC. No commercial re-use. See rights and permissions. Published by BMJ.

${ }^{1}$ School of Nursing, China Medical University, Shenyang, China

${ }^{2}$ Nursing Department, Tongji Hospital, Tongji Medical College, Huazhong University of Science and Technology, Wuhan, China ${ }^{3}$ Humanity and Management College, Shaanxi University of Chinese Medicine, Xianyang, China

${ }^{4}$ College of Humanities and Social Sciences, China Medical University, Shenyang, China

Correspondence to Professor Xin Wang; wxinsmile@qq.com

\section{ABSTRACT}

Objective To explore the latent structure of health financing and the institutional distribution of health expenditure (focused on hospital expenditure) in provinces, autonomous regions and municipalities of mainland China, and to examine how these profiles may be related to their externalising and internalising characteristics.

Study design The study used panel data harvested from the China National Health Accounts Report 2018.

Methods Mainland China's provincial data on health expenditure in 2017 was studied. A latent profile analysis was conducted to identify health financing and hospital health expenditure profiles in China. Additionally, ranksum tests were used to understand the difference of socioeconomic indicators between subgroups.

Results A best-fitting three-profile solution for per capita health financing was identified, with government health expenditure $\left(\chi^{2}=10.137, p=0.006\right)$ and social health expenditure $\left(\chi^{2}=6.899, p=0.032\right)$ varying significantly by profiles. Health expenditure in hospitals was subject to a two-profile solution with health expenditure flow to urban hospitals, county hospitals and community health service centres having significant differences between the two profiles $(p<0.001)$.

Conclusions Per capita health financing and health expenditure spent in hospitals have discrepant socioeconomic characteristics in different profiles, which may be attributed to macroeconomic factors and government policies. The study provided new and explicit ideas for health financing and health policy regulation in China.

\section{INTRODUCTION}

Health expenditure is a macroscopic evaluation index of health service, which reflects the consumption of health in a country or region within a specified period, and significantly weighs on the national economy and people's living quality. ${ }^{1}$ According to the WHO, to achieve universal health coverage, the root causes of problems affecting health economy or policy challenges should be identified. As a result, many countries are reviewing, analysing and revising their regulations on the health economy. ${ }^{34}$ Previous analyses have demonstrated that health expenditure is closely linked with socioeconomic realities. ${ }^{5}$

\section{Strengths and limitations of this study}

It is the first paper using the latent profile method to explore the characteristics of health expenditures in various provinces of China.

- As a nationwide data study, the findings can contribute to interpreting health expenditure within a broader context.

- This study found apparent heterogeneity in health expenditure of provinces in China, which may facilitate the development of regional policy for health service.

- Due to the limited availability of secondary data, we only tested four socioeconomic factors among the latent profiles.

An increasing level of wealth has a positive effect on the demands for healthcare. ${ }^{6}$ However, the extent to which socioeconomic development associates with health financing and health expenditure remains unclear.

China's health financing system runs at the provincial level and the central government's allocation of health expenditure accounts for a small share. Therefore, the level of health financing is closely related to the economic level of the provinces: some provinces with better economic levels mostly provide higher investment in health, whereas the governments with relatively sluggish economies less invest in health financing. ${ }^{7}$ As well, local governments play a leading role in policy design, such as guiding health financing, regulating medical policies, improving the allocation of health resources and providing efficiency in health services. ${ }^{8}$ The direct result exists in the significant regional disparities of healthcare expenditure, the health financing structure and the health financing level. ${ }^{9}$ Meanwhile, the uneven development also manifests between the urban and rural areas. ${ }^{10}$ Income inequality and lopsided local economic growth have some association with health expenditure disparities among different provinces. ${ }^{11} 12$ Analysis of health 
financing needs to factor in as many aspects as possible to give a multifaceted look. In light of this, researchers have developed a growing concern on the regional characteristics of China's health expenditure and interregional differences. For example, Zhen et al studied the catastrophic health expenditure in two provinces with different levels of economic development and highlighted that the government should give more heed to the actual conditions in different provinces of China. ${ }^{13}$ Therefore, it is essential to identify multidimensional patterns or classes of health expenditure in different regions of China and to aid the formulation of interventions tailored to each class' unique characteristics. In a cluster analysis aiming to analyse the health expenditures of 28 provinces in China, the researchers only found convergence by cluster among regions with similar conditions. Still, they found no single convergence among provinces. ${ }^{14} \mathrm{Yu}$ et al also used cluster analysis to analyse the per capita health expenditure and financing structure of 31 provinces of China in 2013, with the results indicating that per capita health expenditure and financing structure appeared not to be commensurate with the economic status in the eastern, central and western provinces. ${ }^{15}$ These studies have attempted to explore the characteristic of health expenditure among regions and partition provinces into smaller similar groups based on individual items (eg, health financing) in China. To our knowledge, researchers have not reached consensus in the subgroups of health financing. They have not identified subgroups of hospital expenses in different provinces of China by examining socioeconomic factors.

In this study, we intended to capture the heterogeneity of provincial health expenditure representativeness rather than focusing on each region individually. To achieve the goal, we used an analytical approach to divide mainland China into representative groups (also specified as profiles). As some previous studies suggested that health economy characteristics may be closely related to internal factors, ${ }^{16}$ we examined whether these subgroups demonstrate associations with some socioeconomic indicators. The advantage of this province-oriented approach was that the impact of each province was not assessed individually but analysed at the group level, which was based on the representative profile of health economics as a whole.

\section{METHODS}

\section{Data collection}

This study was of secondary nature. Provincial data (2017) on health expenditure, health financing and socioeconomic indicators were available from the China National Health Accounts Report 2018. ${ }^{17}$ The report was compiled by the China National Health Development Research Center, a national research institute led by national health commission of China. Taiwan, Hong Kong and Macao were excluded from the sample because data could not be obtained.

\section{Patient and public involvement}

The data used for this study were directly harvested from China National Health Accounts Report. Therefore there was no direct patient and public involvement.

\section{Indicators}

The health financing scheme in mainland China has three sources for all the provinces: government, social and out-of-pocket (OOP) health expenditure. Government health expenditure refers to the government's funds for healthcare, including state financial allocations and health subvention by local governments. Social health expenditure relates to investment from all sectors of the society in health, which reflects the total amount of funds raised from various social healthcare programmes other than from the government in 1 year. OOP health expenditure means private financing from household revenue and comprises of the cash cost of medical services and the medical expenses not fully reimbursed by medicare.

Health expenditure may flow to different aspects, including hospitals, public health facilities, retail sales, some providers of medical goods and so on. However, most of the health expenditures consumed in health institutions. ${ }^{18}$ Therefore, this study focused on hospitals. Sorted by the levels from the highest to the lowest, the Chinese health institution system includes the following structure: urban hospitals (most of them tertiary hospitals) and county hospitals (most of them secondary hospital), which can provide a higher level of medical services, and township health centres and community health service centres, which are responsible for primary healthcare, such as prevention, rehabilitation services and chronic disease management in certain regions. We divided the health expenditure in hospitals into province-based subgroups (also specified as profiles) and compared the socioeconomic differences between subgroups. Four socioeconomic indicators, namely per capita gross domestic product (GDP), per capita total health expenditure, per capita financial allocation for medical and health institutions and per capita government health expenditure were included in the study.

\section{Data analysis}

Numbers (percentages) or the values expressed as a median (IQR) were reported for variables. Latent profile analysis was used to identify several homogeneous, distinct classes of different provinces, autonomous regions and municipalities (all referred to as provinces) based on the constituents of health expenditure. The latent profile models for the best fit were determined by running multiple latent class models, starting with two classes and adding an additional class in each subsequent iteration until the model fit indices deteriorated or the model no longer converged. The following statistical fit indices were used to evaluate the model fit and locate the best-fitting model: Akaike information criterion (AIC), Bayesian information criterion (BIC), sample size-adjusted BIC (SS Adj. BIC) and Lo-Mendel-Rubin 
likelihood (LMR), with smaller values indicating better fit. The bootstrapped likelihood ratio test (BLRT) close to 0 indicates that the current number $(\mathrm{k})$ of profiles is better than (k-1) profiles, and a significant BLRT p value reveals a high degree of the fitting. Entropy, the accuracy of classification of cohort members in latent profiles and profile differentiation, should be higher than 0.7 , and values closer to 1 indicate better classification. ${ }^{19}{ }^{20}$ However, as for all the fit indicators, LMR and $\mathrm{BIC}$ tend to be the robust predictors of a correct number of profiles, while AIC tends to predict profiles poorly. ${ }^{21}$ When determining the number of latent profiles, the interpretability of the classes based on theoretical considerations, the shape of the profiles and the profiles' size are also taken into account. ${ }^{22}$ The identified latent profiles are respectively defined as profile 1 , profile 2 and so on. Then, we gave each profile a label according to its characteristics. The health expenditure was non-normally distributed (based on Shapiro-Wilk tests). To test the differences in health expenditure among province-based latent profiles, Kruskal-Wallis $\mathrm{H}$ test and Mann-Whitney $\mathrm{U}$ test were conducted. The Dunn-Bonferroni post hoc method following a significant Kruskal-Wallis $\mathrm{H}$ test was conducted. A two-sided $\mathrm{p}<0.05$ was deemed to be statistically significant for all tests. The statistical analyses were performed using Mplus V.7.0 (Muthén \& Muthén, Los Angeles, California, USA) and IBM SPSS V.21.0.

\section{RESULTS}

\section{The status of health expenditure in China, 2017}

In 2017, the total health expenditure was $¥ 5259.83$ billion (US\$1 ¥¥6.75, 2017), which accounted for $6.36 \%$ of GDP. The growth rate of total health expenditure was higher than the GDP growth rate $(6.86 \%)$. Per capita health expenditure was $¥ 3783.83$ in 2017 , an increase of $¥ 432.09$ from the previous year. By financing schemes, government health expenditure stood at $¥ 1520.59$ billion (28.91\%), social health expenditure at ¥2225.88 billion $(42.32 \%)$ and OOP health expenditure at ¥1513.36 billion $(28.77 \%)$.

\section{Latent profile analysis: provincial subgroups of per capita health financing in 2017}

The fit indices of the latent profile analysis models showed that the four-profile and five-profile models had lower AIC, BIC and SS Adj. BIC values than the two-profile and three-profile models, but the BLRT values for the fourprofile and five-profile models were not significant. The AIC, BIC and SS Adj. BIC values were lower in the threeprofile model than that in the two-profile model, and entropy values also favoured the three-profile model as the best-fitting one. (For more detailed fit indices of the latent profile models, see online supplementary appendix exhibit 1.). When viewed in totality, the statistical metrics provided evidence that the three-profile model was best suited to the data.

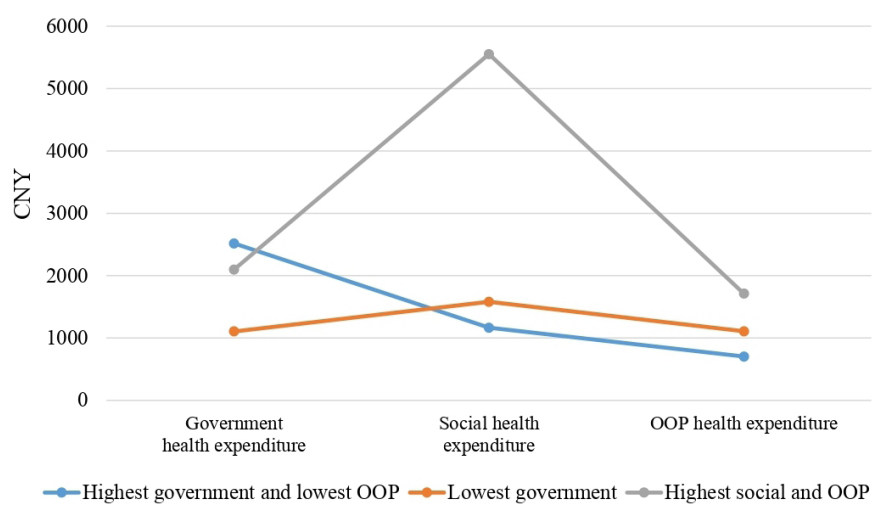

Figure 1 Differences in per capita financing of health expenditure for the three profiles. OOP, out-of-pocket.

Figure 1 graphically displayed the profile means. Profile 1: Tibet and Qinghai were characterised as the high government, low household OOP payment and low social health expenditure profile. We labelled this profile as the highest government and lowest OOP. Profile 2: a large share of 27 provinces, featuring the lowest government health expenditure, and medium household OOP payment and social health expenditure. As such, we labelled this profile as the lowest government. Profile 3: Beijing and Shanghai; we labelled this profile as the highest social and OOP on grounds that health financing in this profile mainly depended on social health expenditure, which was 3.62 and 4.77 times as much as the other two profiles. OOP health expenditure in this profile was also the highest.

The rationality of the latent profile analysis tested by Kruskal-Wallis $\mathrm{H}$ tests showed that per capita government and per capita social health expenditure in the three different profiles were both of significant difference $(p<0.05)$, which showed that the differences among the profiles were considerable, the heterogeneity was satisfying, and the latent profile results were reasonable (table 1).

\section{The distribution of total health expenditure by different levels of health institutions}

In 2017, the percentage of health expenditure in hospitals was the highest $(62.59 \%) .64 .60 \%$ of health expenditures in hospitals were allocated to urban hospitals, followed by $22.01 \%$ to county hospitals, $8.90 \%$ to the township health centres and $4.37 \%$ to community health service centres. (For more detailed distribution of total health expenditures by different levels of health institutions, see online supplementary appendix exhibit 2.)

\section{Latent profile analysis: subgroups were extracted for hospital expense of different provinces in 2017}

Given that health expenditure in hospitals enjoyed the largest share, latent profile analysis was used to classify provinces into homogeneous categories for hospital expenses at different levels. The goodness of fit indices for different profile models was examined. An entropy value closer to 1 indicates a high ability to discriminate 
Table 1 Per capita health expenditure in three profiles by different financing schemes ( $)$

\begin{tabular}{|c|c|c|c|c|c|c|}
\hline \multirow[b]{2}{*}{$\begin{array}{l}\text { Financing } \\
\text { scheme }\end{array}$} & \multicolumn{3}{|c|}{ Median health expenditure (IQR) } & \multirow[b]{2}{*}{$\chi^{2}$} & \multirow[b]{2}{*}{$\begin{array}{l}P \\
\text { value }\end{array}$} & \multirow[b]{2}{*}{$\begin{array}{l}\text { Post hoc test } \\
\text { between profiles }\end{array}$} \\
\hline & $\begin{array}{l}\text { Profile 1: highest } \\
\text { government and lowest } \\
\text { OOP }(n=2)\end{array}$ & $\begin{array}{l}\text { Profile 2: lowest } \\
\text { government }(n=27)\end{array}$ & $\begin{array}{l}\text { Profile 3: highest social } \\
\text { and OOP }(n=2)\end{array}$ & & & \\
\hline $\begin{array}{l}\text { Government } \\
\text { health } \\
\text { expenditure }\end{array}$ & 2516.07 (2147.55-2884.59) & 1099.87 (996.78-1220.08) & 2096.59 (1858.02-2335.16) & 10.137 & 0.006 & $\begin{array}{l}\text { Profile } 1>\text { Profile } 2 \\
(p=0.016) \\
\text { Profile } 3>\text { Profile } 2 \\
(p=0.024)\end{array}$ \\
\hline $\begin{array}{l}\text { OOP health } \\
\text { expenditure }\end{array}$ & 700.62 (216.92-1184.32) & $1065.29(912.84-1232.15)$ & $1710.16(1652.05-1768.26)$ & 4.921 & 0.085 & - \\
\hline
\end{tabular}

${ }^{*}$ Dunn-Bonferroni test was conducted for post hoc pairwise comparison. OOP, out-of-pocket.

between different profiles. The entropy value of the twoprofile model was 0.999 , which was closer to 1 than the other latent profile models. BIC, LMR and BLRT values were all lower for the two-profile model when compared with the three-profile model and the four-profile model. As for AIC, its value for the two-profile model was slightly higher than the three-profile model and the four-profile model. When viewed in totality, these statistical indicators provided evidence that a two-profile model was the best fit for the data. (For more detailed fit indices of the latent profile models, see online supplementary appendix exhibit 3.)

Profile 1, labelled as high county and township, which consisted of 27 provinces, had more substantial health expenditure flow to the county hospitals and township health centres. Profile 2 embraced Beijing, Shanghai, Tianjin and Guangdong. Given that Profile 2 had more massive expenditure flow to the urban hospitals and community health service centres, and smaller expenditure flow to county hospitals and township health centres, it was identified as the high urban and community profile (figure 2).

Furthermore, Mann-Whitney $\mathrm{U}$ tests were used to explore the differences in hospital expenses between the two profiles. Table 2 shows that the amounts of health expenditure flow to urban hospitals, county hospitals,

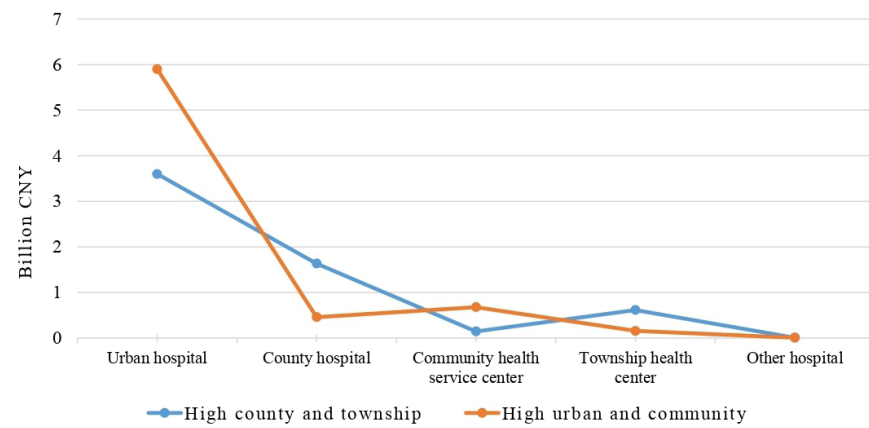

Figure 2 Health expenditure flowed to different levels of hospitals in the two latent profile catalogue. community health service centres and township health centres were significantly different between the two profiles $(\mathrm{p}<0.05)$, the heterogeneity was satisfying, and the grouping results were appropriate.

Results of Mann-Whitney $\mathrm{U}$ tests revealed that there were significant differences in per capita total health expenditure $(\mathrm{p}=0.004)$, per capita GDP $(\mathrm{p}=0.003)$, per capita financial allocation for medical and health institutions $(\mathrm{p}=0.036)$ and per capita government health expenditure ( $\mathrm{p}=0.029)$ between the two latent profiles (table 3$)$.

\section{DISCUSSION}

This study provided a cross-sectional description of health expenditure in China, with two key findings. First, through the latent profile method, we derived discriminative profiles at the subnational level by characteristics of health expenditures and health financing. Second, Chinese health financing and hospital health expenditure have regional disparities, with both resource availability and government policies playing an essential role in the local health economy.

Health financing systems affect almost all goals of healthcare and play an essential role in improving equality, risk protection and efficiency. ${ }^{23}$ Adequate and stable health financing is critical. ${ }^{24}$ China has a vast territory, featuring itself with a wide assortment of ethnic groups, customs, traditions, medical conditions, health literacy levels and other aspects. ${ }^{25}{ }^{26}$ Chinese economic development also has regional disparities, which weighs on health financing. Meanwhile, the allocation of government resources can also play a role, which is a multifaceted balance among competing tradeoffs. Therefore, health financing is complicated and restricted by many factors. However, for the sake of simplicity, studies, including China's health statistics yearbook often discuss the regional differences of health expenses based on geographical locations, such as east, central and west of China. ${ }^{28}$ To address a more reasonable model of health financing in different 
Table 2 Health expenditure in different levels of hospitals between the two profiles (billion CNY (¥))

\begin{tabular}{|c|c|c|c|c|}
\hline \multirow[b]{2}{*}{ Variables } & \multicolumn{2}{|l|}{ Median health expenditure (IQR) } & \multirow[b]{2}{*}{$\mathbf{Z}$} & \multirow[b]{2}{*}{ P value } \\
\hline & High county and township $(n=4)$ & High urban and community $(n=27)$ & & \\
\hline Urban hospital & $3.548(3.405-3.807)$ & $5.702(5.480-6.325)$ & -3.182 & 0.001 \\
\hline Community health service centre & $0.143(0.091-0.173)$ & $0.674(0.493-0.863)$ & -3.182 & 0.001 \\
\hline Township health centre & $0.638(0.496-0.733)$ & $0.129(0.000-0.318)$ & -3.123 & 0.002 \\
\hline
\end{tabular}

provinces of China, latent profile analysis was used. We found three statistically and practically meaningful province-based profiles (subgroups) for per capita health financing. Also, the subgroups we have obtained did not show very significant geographic convergence. The result can be explained by the social determinants of health framework, which includes social position (eg, races and income), healthcare system (eg, material conditions, availability and accessibility) and socioeconomic and political context (eg, governance and policy) ${ }^{29}$ Of all the determinants, we speculate that health resources allocation played a crucial role. The highest government and lowest OOP profile, Tibet and Qinghai, represented the highest government health expenditure and the lowest OOP and social health expenditure, which can be corroborated by a relatively high level of government investment and policy support, smaller regional population and low per capita economic output. The highest social and OOP profile, Beijing and Shanghai, reported prominent social health expenditure. In China, social health expenditure mainly comes from non-governmental agency spending on health, private insurance and social insurance programmes, with the latter being mandatorily taken from the paychecks of the insured. While Beijing and Shanghai top the average salaries chart in mainland China in recent years, social insurance premiums of the two municipalities also outrun other provinces. Social health expenditure enables providers to benefit from residual income while being responsible for care outcomes, thus incentivising providers to provide patients with appropriate types and levels of care. ${ }^{30}$ As recommended by a comprehensive study of health spending in 195 countries for 21 years, increased levels of social health expenditure should be a priority toward universal health coverage. ${ }^{31} \mathrm{~A}$ more competitive social health expenditure would help alleviate the severe problems of inadequate and disequilibrium of health financing faced by the current system.

China has faced enormous challenges in addressing health inequalities in regions with various socioeconomic development. ${ }^{32}$ Previous studies, which grouped China's health expenditure based on geographical divisions, didn't show prominent disparities in health expenditure among east, central and west China. ${ }^{33}$ As we know that economic factors affect health expenditure, our findings revealed that grouping based on economic levels might neither be reasonable. For instance, eastern coastal regions (Shanghai, Jiangsu, Zhejiang and Guangdong) share a similarity in commercial activities and affluence. They were not grouped into the same profile, with Shanghai being singled out from the area and joining Beijing to form a profile alone. Such grouping may not be simply attributed to economic factors. The inherent characteristics and system design of different provinces, such as the funding sources, financing levels and so on, may have some effect. ${ }^{34}$ As showed in figure 1, the highest social and OOP profile (Beijing and Shanghai) had the highest level of social health expenditure, indicating that the two municipalities were a lot more attractive to social and private funds than affluent coastal regions. The dominant difference in health spending financed by social health expenditure sources underscores the gap and potential to expand non-governmental agency payment

Table 3 Comparison of socioeconomic factors between the two latent profiles ( $¥)$

\begin{tabular}{|c|c|c|c|c|}
\hline \multirow[b]{2}{*}{ Variables } & \multicolumn{2}{|l|}{ Median health expenditure (IQR) } & \multirow[b]{2}{*}{$\mathbf{Z}$} & \multirow[b]{2}{*}{$P$ value } \\
\hline & High county and township $(n=4)$ & High urban and community $(n=27)$ & & \\
\hline $\begin{array}{l}\text { Per capita total health } \\
\text { expenditure }\end{array}$ & 7062.45 (4490.45-9722.43) & 3644.80 (2938.20-4010.10) & -2.887 & 0.004 \\
\hline Per capita GDP & 126634.00 (92 357.50-128404.00) & 46674.00 (42 060.00-60 199.00) & -3.006 & 0.003 \\
\hline $\begin{array}{l}\text { Per capita financial allocation } \\
\text { for medical and health } \\
\text { institutions }\end{array}$ & $934.50(625.25-1355.50)$ & $518.50(373.25-707.75)$ & -2.075 & 0.038 \\
\hline $\begin{array}{l}\text { Per capita government health } \\
\text { expenditure }\end{array}$ & 1575.69 (1210.27-2218.10) & $1062.77(883.77-1231.33)$ & -2.180 & 0.029 \\
\hline
\end{tabular}

GDP, gross domestic product. 
mechanisms in both the highest government and lowest OOP profile and the lowest government profile.

As the percentage of health expenditure in hospitals was the highest, we further explored the distribution characteristics of hospital expenditure. The provinces with the highest hospital expenditure in urban hospitals also spend a lot in community health service centres. The health expenditures in both the urban hospital and the community health service centre were the highest for provinces in the high urban and community profile and the lowest in the high county and township profile. Understandably, patients tend to visit a medical institution close to home. ${ }^{35}$ The feature of community health institutions adapts to provide a more accessible health service. Compared with the situation in the provinces of the high county and township profile, most residents in the high urban and community profile can access health service timelier and more convenient. Take Shanghai (belongs to the high urban and community profile) for example; community health service coverage is extensive, and more than $97 \%$ of residents who lived in Shanghai can have access to medical facilities, including community medical centres, within a 15 -minute walk. ${ }^{36}$ Correspondingly, in the Sichuan province (belongs to the high county and township profile), only $39.4 \%$ of the population had access to the nearest hospital within a 30-minute drive. ${ }^{37}$ Of note, health expenditure flowing to county hospitals and township health centres in the high county and township profile outran the high urban and community profile, which might be explained by the fact that the four provinces of the high urban and community profile are highly urbanised areas, and that county hospitals and township health centres are rare in the regions. As a supplement, the primary care systems provide the residents in the high urban and community profile some convenient, person-centred health service at a lower cost than urban hospitals.

This study found that per capita GDP, per capita financial allocation for medical and health institutions, and per capita government health expenditure in the high urban and community profile were significantly higher than the high county and township profile. Hospital expense is driven by the availability of resources, such as per capita GDP and fiscal funding for health services. Where medical resources are abundant, residents have a higher awareness of healthcare and pay more attention to the prevention and control of diseases. ${ }^{38}$ Reversely, in most rural areas of China, primary healthcare services are of poor quality, which makes residents reluctant to seek healthcare there. ${ }^{39}$ The payment ability served as a critical factor, as residents with higher incomes are more concerned about their health. ${ }^{40}$ The inequities in access to healthcare might exist as a result of income differences within the provinces. There were significant differences in per capita of total health expenditure between the two profiles, which could be explained by the disparities in the medical insurance system and policies. Insurance reduces the OOP health expenditure and improves access to medical care. ${ }^{41}$ However, the variations in reimbursement levels between municipalities under the direct administration of central government (eg, Beijing, Shanghai and Tianjin) and other provinces are remarkable. ${ }^{42}$ As hospital level had a significant impact on the total health expenditure, the mean total cost in high-level hospitals towers lower-level ones. ${ }^{43}$ However, very high health spending has not transformed into better access to quality care for all populations. ${ }^{44}$ Broader policy development may promote optimal allocation of medical resources,${ }^{45}$ which implies that differences between the profiles in this study could ultimately be used for directing more resources to provinces belonging to the high county and township profile. Policy support will continue to be required, but it is noted that such support does not replace efforts within the regions. Studies have shown that significant progress can be made at very low levels of expenditure when it comes to access to healthcare. ${ }^{46}$ Therefore, it is of the essence to uphold proper governance. Regional health resources adjustment should centre on how well they play a role and affect health system goals such as the quality and service range. Therefore, the focus of health system reform should not be projected to the adjustment of resident preference for the health sector but shift to the rational use of existing resources based on existing medical institutions, and on improving the allocation and technical efficiency.

Several limitations should be noted. First, because of the limited availability of secondary data, health financing and health expenditure were measured only at the population level, not at the individual level. However, differences at the population level can be significant at a personal level. Inequity may be veiled by equality. Therefore, more attention should be paid to the profiles that presented high OOP health expenditure and the provinces with ailing medical conditions. Meanwhile, there was no information on potential confounding factors, and this study was an unadjusted analysis. Second, due to limitations in the data set, the socioeconomic factors included in this study were limited, and other socioeconomic factors (eg, medical infrastructure and transportation) that may influence health expenditure requires further research.

\section{CONCLUSIONS}

This paper takes a snapshot of China's 2017 health expenditure, for which not only socioeconomic and policy orientations but also regional investment attraction may play a role. This study innovatively used latent profile analysis to identify distinct subgroups of provinces representing unique health financing and hospital health expenditure characteristics. We found meaningful profiles of provinces that allowed for exploring the characteristics of health expenditure. From the perspective of per capita health expenditure, aside from Beijing and Shanghai (the highest social and OOP profile), and Qinghai and Tibet (the highest government and lowest OOP profile), 
the rest 27 provinces, which cover the majority of the population in mainland China, were grouped into the lowest government profile. Therefore, we suggest that policymakers give more heed to this profile regarding resource allocation and policy support. From the facet of hospital expense, aside from the high urban and community profile (Beijing, Shanghai, Tianjin and Guangdong), the rest 27 provinces were grouped into the high county and township profile, meaning health economic issues of the largest share of the population covering the largest share of territory need attention. Taking into account the United Nations sustainable development goals, we recommend that the government develop targeted policy responses to health financing, improve the quality of health services in low-grade hospitals, diversify fundraising and reimbursement policy, and promote the construction of hierarchical medical and referral system in China.

Contributors SZ designed the overall study, collected and analysed the data, interpreted results and prepared the first draft of the manuscript. XW designed the study, coordinated the data collections and guided the analysies. MZ advised on the initial design of the manuscript and provided feedback on subsequent revisions. J0 reviewed and provided feedback on the later versions of the manuscript. All authors read and approved the final manuscript.

Funding This study was funded by the National Natural Science Foundation of China (71673299), the project of nursing and care branch of China association of gerontology and geriatrics 2019-2020(2019-hzh-004) and the scientific research projects of Nursing College, China Medical University (2019HL-13).

\section{Competing interests None declared.}

Patient and public involvement Patients and/or the public were not involved in the design, or conduct, or reporting or dissemination plans of this research.

\section{Patient consent for publication Not required.}

Ethics approval This study did not require the participation of human subjects. The information was anonymous, and no data related to individuals were collected or were accessible. As a secondary analysis of existing data, ethics approval was therefore not necessary.

Provenance and peer review Not commissioned; externally peer reviewed.

Data availability statement The data used to support the findings of this study are available from the corresponding author upon request.

Open access This is an open access article distributed in accordance with the Creative Commons Attribution Non Commercial (CC BY-NC 4.0) license, which permits others to distribute, remix, adapt, build upon this work non-commercially, and license their derivative works on different terms, provided the original work is properly cited, appropriate credit is given, any changes made indicated, and the use is non-commercial. See: http://creativecommons.org/licenses/by-nc/4.0/.

ORCID iD

Xin Wang http://orcid.org/0000-0001-7591-0103

\section{REFERENCES}

1 Chen C, Pan J. The effect of the health poverty alleviation project on financial risk protection for rural residents: evidence from Chishui City, China. Int J Equity Health 2019;18:79.

2 Kutzin J, Witter S, Jowett M, et al. Developing a national health financing strategy: a reference guide. Geneva: World Health Organization, 2017.

3 Xu K, Soucat A, Kutzin J, et al. Public spending on health: a closer look at global trends. Geneva: World Health Organization, 2018.

4 Gheorghe A, Straehler-Pohl K, Nkhoma D, et al. Assessing the feasibility and appropriateness of introducing a national health insurance scheme in Malawi. Glob Health Res Policy 2019;4:13.

5 Zhai T, Goss J, Li J. Main drivers of health expenditure growth in China: a decomposition analysis. BMC Health Serv Res 2017;17:185.
6 Rahman MM, Khanam R, Rahman M. Health care expenditure and health outcome nexus: new evidence from the SAARC-ASEAN region. Global Health 2018;14:113.

7 Wang YX. Government health expenditure Structure-Based on provinces and international comparison. Advances in Social Sciences 2017;06:1410-7.

8 World Health Organization. Healthy China: deepening health reform in China. Washington, DC: World Bank, 2019.

9 Li X, Gao QQ, Qiu LJ, et al. Research on the Structure and Equity Changes of China's Health Financing Based on Concentration Index. Chinese Health Economics 2019;38:37-41.

10 Min $\mathrm{R}$, Wang $\mathrm{H}$, Zhang $\mathrm{X}$, et al. Facing the urban-rural gap in patients with chronic kidney disease: evidence from inpatients with urban or rural medical insurance in central China. PLoS One 2018;13:e0209259.

11 Kumar K, Singh A, Kumar S, et al. Socio-Economic differentials in impoverishment effects of out-of-pocket health expenditure in China and India: evidence from who SAGE. PLoS One 2015;10:e0135051.

12 Zhang G, Zhang L, Wu S, et al. The convergence of Chinese County government health expenditures: capitation and contribution. $B M C$ Health Serv Res 2016;16:408.

13 Zhen X, Zhang H, Hu X, et al. A comparative study of catastrophic health expenditure in Zhejiang and Qinghai Province, China. BMC Health Serv Res 2018:18:844.

14 Chou WL, Wang Z. Regional inequality in China's health care expenditures. Health Econ 2009;18 Suppl 2:S137-46.

15 YR Y, Hao HF, Liu QY, et al. Analysis on regional differences of health expenditure and its financing structure in China. Chinese Journal of Social Medicine 2018:35:513-7.

16 Hlafa B, Sibanda K, Hompashe DM. The impact of public health expenditure on health outcomes in South Africa. Int J Environ Res Public Health 2019;16:E2993.

17 China National Health Development Research Center. China National health accounts report 2018. Beijing: China National Health Development Research Center, 2018.

18 Younis MZ, Jaber S, Mawson AR, et al. Estimating the unit costs of public hospitals and primary healthcare centers. Int J Health Plann Manage 2013;28:320-32.

19 Masyn KE. Latent class analysis and finite mixture modeling. in: the Oxford Handbook of quantitative methods. Vol 2. statistical analysis. New York: Oxford University Press, 2013.

20 Wang MC. Latent variable modeling and MPLUS application. Chongqing: Chongqing University Press, 2018.

21 Tein J-Y, Coxe S, Cham H. Statistical power to detect the correct number of classes in latent profile analysis. Struct Equ Modeling 2013;20:640-57.

22 Orri M, Pingault J-B, Rouquette A, et al. Identifying affective personality profiles: a latent profile analysis of the affective neuroscience personality scales. Sci Rep 2017;7:4548.

23 World Health Organization. Everybody business: strengthening health systems to improve health outcomes: who's framework for action. Geneva: World Health Organization, 2007.

24 Sajadi HS, Ehsani-Chimeh E, Majdzadeh R. Universal health coverage in Iran: where we stand and how we can move forward. Med J Islam Repub Iran 2019;33:9.

25 Del Giudice T, Cicia G, Grunert KG, et al. New trends in the Chinese diet: cultural influences on consumer behaviour. Ital J Food Saf 2016;5:5273.

26 Lin X, Cai M, Tao H, et al. Insurance status, inhospital mortality and length of stay in hospitalised patients in Shanxi, China: a crosssectional study. BMJ Open 2017;7:e015884.

27 National health commission of the People's Republic of China. China's Health Statistics Yearbook(2018. Beijing: China Union Medical University Press, 2018.

28 LQ L, Zhong MQ, Yi F, et al. Analysis on the equity of health financing level of health in China. Chinese Health Economics 2018;37:57-61.

29 Venkatapuram S, Bell R, Marmot M. The right to sutures: social epidemiology, human rights, and social justice. Health Hum Rights 2010;12:3-16.

30 Liu GG, Vortherms SA, Hong X. China's health reform update. Annu Rev Public Health 2017;38:431-48.

31 Global Burden of Disease Health Financing Collaborator Network. Past, present, and future of global health financing: a review of development assistance, government, out-of-pocket, and other private spending on health for 195 countries, 1995-2050. Lancet 2019;393:2233-60.

32 Tang S, Meng Q, Chen L, et al. Tackling the challenges to health equity in China. Lancet 2008;372:1493-501.

33 Gao Y, LQ L. Thiel coefficient analysis on equity of health financing in China. Chinese Journal of Health Statistics2018;35:600-2. 
34 Beijing Municipal Medical Insurance Bureau. Notice on adjusting the Fundraising standards for basic medical insurance for urban and rural residents and relevant policies, 2019. Available: http:// ybj.beijing.gov.cn/xxgk/zcwj/zcfg/201911/t20191111_499501.html [Accessed 17 Nov 2019].

35 Varkevisser M, van der Geest SA. Why do patients bypass the nearest hospital? an empirical analysis for orthopaedic care and neurosurgery in the Netherlands. Eur J Health Econ 2007;8:287-95.

36 Xiong X, Bai G, Jin C, et al. A method of calculating and visualizing spatial accessibility to health services based on the nearest distance method. Chin Health Resour 2016;19:270-4.

37 Pan J, Liu H, Wang X, et al. Assessing the spatial accessibility of hospital care in Sichuan Province, China. Geospat Health 2015;10:384.

$38 \mathrm{Xu}$ C, Liang Z, Luo Y-J. Role of medical resource level in iodine deficiency disorder. Mil Med Res 2017:4:18.

39 Cheng J-M, Yuan Y-X, Lu W, et al. Primary health care in China: is China's health reform reform for the whole nation? Prim Health Care Res Dev 2017;18:398-403.
40 Hao Y, Liu S, Lu Z-N, et al. The impact of environmental pollution on public health expenditure: dynamic panel analysis based on Chinese provincial data. Environ Sci Pollut Res Int 2018;25:18853-65.

41 Zang S, Zhan H, Zhou L, et al. Research on Current Curative Expenditure among Lung Cancer Patients Based on the "System of Health Accounts 2011": Insights into Influencing Factors. J Cancer 2019;10:6491-501.

42 Dong YY, Zhang L, Yang YL, et al. A comparative study on children's basic medical insurance system and policies in four municipalities in China. J Shanghai Jiaotong Univ 2018;38:670-5.

43 Yin X, Xu Y, Man X, et al. Direct costs of both inpatient and outpatient care for all type cancers: the evidence from Beijing, China. Cancer Med 2019;8:3250-60.

44 Dieleman JL, Sadat N, Chang AY, et al. Trends in future health financing and coverage: future health spending and universal health coverage in 188 countries, 2016-40. The Lancet 2018;391:1783-98.

45 Jacobs $E$. The politics of the basic benefit package health reforms in Tajikistan. Glob Health Res Policy 2019;4:14.

46 Jowett M, Brunal MP, Flores G, et al. Spending targets for health: no magic number. Geneva: World Health Organization, 2016. 